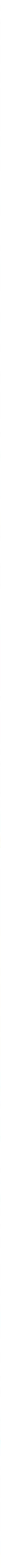




\title{
Influence of Trunk or Bough Shaking on the Performance and Costs of Mechanical Harvesting of Olives
}

\author{
J. Peça, A. Dias and A. Pinheiro
}

Universidade de Évora, Évora - Portugal

L. Santos

Departamento de Olivicultura da E.N.F.V.N., Elvas - Portugal

A. Almeida

Escola Superior Agrária de Bragança, Bragança - Portugal

J. Lopes

Dir. Regional de Agricultura de Trás-os-Montes, Mirandela.- Portugal

D. Reynolds

R\&O, Monte da Granja, Estremoz - Portugal

Keywords: olives / mechanical harvesting / shakers / costs

\begin{abstract}
Field trials carried out in Portugal showed the penalty to be paid, both in terms of work rate and costs, whenever, due to tree geometry and size, trees had to be bough shaked rather than the normal trunk shaking. If an olive orchard with trees requiring two bough shakings could be adapted to an entirely trunk shaking orchard, simulation shows an increment between $9 \%$ and $33 \%$ in the work rate at harvesting and a reduction between $4 \%$ and $22 \%$ in harvesting cost per kilogram of olive, assuming a 4000 trees size orchard. The data collected is regarded to be very useful for decision support, particularly for those farmers owning less adapted olive orchards, aiming to adopt mechanized harvesting.
\end{abstract}

\section{INTRODUCTION}

In Portugal, where most of the olive orchards were established long before the introduction of harvest equipment (tree shakers), it is very common to find trees, that due to size and geometry, require bough shaking instead of the simpler trunk shaking, in order to keep harvest efficiency. Field trials were performed in different regions of Portugal to get the necessary data in order to make possible the simulation of the work rates and harvesting costs, when $40 \%, 20 \%$ and $0 \%$ of the total number of the trees in a orchard need to be bough shaked.

\section{MATERIAL AND METHODS}

Field trials took place in three different olive orchards, being site 1 and 2 in Alentejo (Southern Portugal) and site 3 in Trás-os-Montes (Northeast of Portugal): Site 1 - Calada: a 50 year old olive orchard of the local variety Galega, planted at an array of 123 trees per hectare $(9 \mathrm{~m} \times 9 \mathrm{~m})$. A total of 60 trees were evaluated in the trial, divided by 2 plots, selected by randomisation. Site 2 - Vale da Telha: a 35 year old olive orchard of Galega variety, planted at an array of 100 trees per hectare $(10 \mathrm{~m} \times 10 \mathrm{~m})$. A total of 88 trees were evaluated in the trial, divided by 3 plots, selected by randomisation. Site 3 Romeu: a 50 year old olive orchard of the local varieties Verdeal $(37 \%)$ and Cobrançosa $(34 \%)$ and three other less important varieties. It is planted at an array of 117 trees per hectare $(9 \mathrm{~m} \times 9,5 \mathrm{~m})$. A total of 42 trees were evaluated in the trial, divided by 2 plots, selected by randomisation.

Harvest was performed by an impact shaker, mounted on the front loader of a four wheel drive tractor of $50 \mathrm{~kW}$, being the olives collected on a $10 \mathrm{~m} \times 10 \mathrm{~m}$ canvas placed under the canopy projection, and moved by 4 women. Meanwhile, in a parallel row, a 
second group was placing another canvas under the next tree to be shaked. A second tractor and trailer were standing by to collect the olives when canvas became too heavy, as well as to provide transport to processing. In each trial the following measurements were taken: Time spent vibrating each tree through its trunk (T1); total time spent in each tree requiring two bough shaking (T2); total time spent in each tree requiring three bough shaking (T3); total time spent in each tree requiring four bough shaking (T4); time spent in each displacement between two consecutive trees (TD); total mass of olives harvested per plot.

To compute costs, values are reported to 1998, and include the sequence of operations from tree shaking up to the complete loading of a farm trailer used for transport; labour costs, for the gang of 8 women, are based on contractors charges (EURO/kg), a typical situation in Southern Portugal (sites 1 and 2), and on local daily rates (EURO/working day), for seasonal workers in the Northeast of Portugal (site 3); ownership and operating costs of tractors, front-end-loader and trailer are based on official tables published by the Ministry of Agriculture assuming 800 hours of annual use for the tractors; the costs relative to the shaker were obtained from information supplied by the manufacturer; the annual use of the shaker was computed from the work rates measured in the field and from the dimension of the olive orchard.

\section{RESULTS}

From the actual values in each one of the sites, the average values of T1, T2 and TD were computed (Table I) and used to calculate the work rates expected in hypothetical orchards (Table II), where trees requiring two bough shaking and trees requiring trunk shaking varied in the following proportions: $40 \%$ two bough shaking trees; $60 \%$ trunk shaking trees or $20 \%$ two bough shaking trees; $80 \%$ trunk shaking trees or $0 \%$ two bough shaking trees; $100 \%$ trunk shaking trees, being the work rate given in trees per hour, by:

$$
W R=\frac{3600}{T+T D} \text {, being } \mathrm{T} \text { the average time required by each tree, and TD the average }
$$

displacement time between consecutives trees. Harvesting costs per kilogram of olive were computed from the following expressions, which take into account the type of deal established with labour:

contract basis: hour basis:

$$
H C=\left(\frac{M H C}{W R}+\frac{V A C}{T N T}\right) \times \frac{1}{Y P T}+C C \quad H C=\left(\frac{M H C}{W R}+\frac{V A C}{T N T}+\frac{8 L H R}{W R}\right) \times \frac{1}{Y P T}
$$

$\mathrm{HC}$ - harvest cost in EURO/kg; MHC - hourly cost with machinery not exclusively assigned to olive harvesting (tractors, trailer and front-end-loader), in EURO/hour; WR work rate, in trees/hour; VAC - annual costs with equipment exclusively assigned to olive harvesting (shaker and canvas), in EURO/year; TNT - total number of trees; YPT average yield per tree, in $\mathrm{kg} /$ tree; $\mathrm{CC}$ - local contractor charges (only labour), in EURO/kilogram of olives harvested; LHR - hourly labour charges, in EURO/hour/labour. Simulated costs for the hypothetical orchards of table II with 2000, 4000 and 6000 trees are presented in table III.

\section{DISCUSSION AND CONCLUSIONS}

The experiments were performed in real working conditions, as is reflected on the large variation in the data as shown in Table I. Since the operator was free to judge the moment to stop shaking, is reasonable to assume that this resulted in shorter shaking times in smaller trees or in those with lower yields, than in larger and in more productive trees. Furthermore those trees presenting long flexible shoots, as a result of bad pruning practice, required always a longer vibrating time. The movement from one tree to the next is, in fact, a sequence of three different stages: driving backwards from one tree; driving faster towards the next tree; slow approach to the trunk or bough to be vibrated.

Timeliness is crucial, since during the months of November up to January, weather conditions, particularly rain and wind, may jeopardise harvest. As expected, there is an 
improvement in the work rates when the number of trees requiring bough shaking is reduced. Values from $20 \%$ to $33 \%$ of increment were found (Table II) when simulating hypothetical orchards with $40 \%$ of trees requiring two bough shaking, being converted entirely to trunk shaking. Similar calculations from orchards with $20 \%$ of trees requiring two bough shaking resulted in increments from $9 \%$ to $16 \%$. Trimming two bough trees, making possible trunk shaking, leads also to lower harvesting costs, as shown in table III. There are three items that add up to the total value of cost per kilogram: cost assigned to the use of non specific equipment and labour (tractors, trailer and drivers); labour costs assigned to the handling of the canvas; costs assigned to the use of specific equipment (shaker and canvas). The latter has no interference in this process since it is assumed that the total annual cost of the shaker is the same regardless of the proportion of bough shaking trees, and it is assumed that the orchard will reach the same yield level, within a few years after trimming. Otherwise, since a larger amount of olives can be harvested in the same period of time, when every tree is vibrated at the trunk, one should expect to find lower costs, per kilogram of olives, allocated to non specific machinery (tractors, trailers and drivers). For the same reason a reduction in cost should be expected with handling labour when payment is done by the hour (site 3 ). This item, however, has no influence if workers for canvas handling have been contrated at a fixed charge for kilogram delivered (sites 1 and 2).

Within this framework, and taking the example of 4000 tree orchard, where $40 \%$ of the trees required the individual shaking of two boughs, the reduction in harvesting costs assuming the total number of trees could be trunk shaken instead, would be between $7 \%$ and $10 \%$ in sites 1 and 2, where handling labour is contracted at a fixed rate per kilogram delivered, and $22 \%$ in site 3 , where labour is paid at an hourly basis. The lower gains in the first two sites result from the fixed rate established in the contract.

The same outcome would be reached regardless of the size of the orchard $(2000$, 4000 or 6000 trees), with only minor differences to the above presented percentages. This is due to the fact that the reduction in harvesting cost per kilogram is mainly influenced by the gains in the work rate, which are assumed to be same regardless of the size of the orchard.

To help olive growers to decide upon making the adaptation of their orchards to an all trunk shaking orchard, this paper presented information regarded as relevant. For the longer run, in the assumption that the yield level can be maintained, the farmer may find in the values presented a guideline to predict new harvesting costs, from which the total production cost and finally the new profit margin may be estimated.

\section{ACKNOWLEDGEMENTS}

The authors wish to thank the olives growers for their collaboration and the research programme PAMAF I\&D 2072 for the financial support. 


\section{Tables}

Table 1. Results found, according to the measurements taken in the field

\begin{tabular}{lcccc}
\hline & Average time(seconds) & S.D. (seconds) & C.V. & $\begin{array}{c}\mathrm{N}^{\circ} \text { of } \\
\text { observations }\end{array}$ \\
\hline SITE 1 & $\mathrm{T} 1=33,3$ & 18,82 & $56,5 \%$ & 24 \\
Average yield & $\mathrm{T} 2=80,0$ & 28,47 & $35,6 \%$ & 18 \\
per tree=19,5 kg & $\mathrm{T} 3=148,1$ & 53,37 & $36,0 \%$ & 11 \\
& $\mathrm{~T} 4=216,8$ & 59,75 & $27,6 \%$ & 6 \\
& $\mathrm{~T} 7=309,0$ & & $117,0 \%$ & 59 \\
\hline SITE 2 & $\mathrm{TD}=67,6$ & 79,07 & $122,6 \%$ & 63 \\
Average yield & $\mathrm{T} 1=22,1$ & 27,15 & $77,5 \%$ & 23 \\
per tree=13,3 kg & $\mathrm{T} 2=87,3$ & 67,68 & $71,2 \%$ & 86 \\
\hline SITE 3 & $\mathrm{TD}=75,4$ & 53,67 & $52,1 \%$ & 30 \\
Average yield & $\mathrm{T} 1=16,7$ & 8,69 & $33,4 \%$ & 8 \\
per tree=16,5 kg & $\mathrm{T} 2=102,1$ & 34,06 & $15,6 \%$ & 4 \\
& $\mathrm{~T} 3=195,3$ & 30,48 & & 41 \\
\hline
\end{tabular}

Table 2. Work rate (trees/hour)

\begin{tabular}{llll}
\hline Percentage of two boughs from the total & SITE 1 & SITE 2 & SITE 3 \\
\hline $40 \%$ & 30 & 29 & 27 \\
$20 \%$ & 33 & 33 & 31 \\
$0 \%$ & 36 & 37 & 36 \\
\hline
\end{tabular}

Table 3. Harvesting costs in cents $\left(10^{-2}\right.$ EURO) per kilogram

\begin{tabular}{lcccc}
\hline & Percentage of two boughs & \multicolumn{3}{c}{ Total number of trees } \\
\cline { 2 - 5 } & shaking from the total & 2000 & 4000 & 6000 \\
\hline \multirow{3}{*}{ SITE 1 } & 40 & 23,75 & 21,0 & 20,0 \\
& 20 & 23,0 & 20,25 & 19,25 \\
\hline \multirow{2}{*}{ SITE 2 } & 0 & 22,25 & 19,5 & 18,75 \\
& 40 & 30,5 & 26,5 & 25,0 \\
& 20 & 29,0 & 25,0 & 23,5 \\
SITE 3 & 0 & 27,75 & 23,75 & 22,5 \\
& 40 & 26,25 & 23,0 & 21,75 \\
& 20 & 23,5 & 20,5 & 19,25 \\
& 0 & 21,25 & 18,0 & 17,0 \\
\hline
\end{tabular}

